\title{
ENSINO DA SAÚDE NO CURRÍCULO DO CURSO DE SERVIÇO SOCIAL DA UECE: percepções das estudantes
}

\author{
Teaching of health in the curriculum of the Social Service course on UECE: the \\ students' perceptions
}

\author{
Rebeca da Silva Costa ${ }^{1}$ \\ Yashmin Michelle Ribeiro de Araujo $^{2}$ \\ Cristiane Maria Marinho ${ }^{3}$
}

RESUMO: O debate em torno do aprofundamento ou não de determinados conteúdos nos currículos dos cursos de Serviço Social merece destaque nas investigações a respeito da formação profissional. Sendo assim, este artigo objetiva refletir sobre as percepções de estudantes do curso de Serviço Social da UECE, estagiárias no campo da saúde, no que se refere ao ensino do conteúdo da saúde no currículo deste curso de graduação. Para tanto, adotamos a pesquisa de natureza qualitativa, com o uso dos delineamentos da pesquisa bibliográfica, documental e de campo, utilizando a entrevista semiestruturada com cinco estudantes para a coleta dos dados. Os resultados desta pesquisa evidenciaram a compreensão sobre a necessidade de uma formação generalista crítica conforme propõe a ABEPSS, mas a prevalência da percepção entre as estudantes entrevistadas sobre a necessidade de disciplinas específicas para tratar do conteúdo da saúde, tendo em vista a importância dos espaços da saúde como campos de trabalho privilegiados para os/as assistentes sociais e como espaços de aprendizagem para os/as estagiários.

Palavras-chave: Formação profissional. Saúde. Serviço Social.

ABSTRACT: The debate about the deepening or not of certain contents in the curricula of the courses of Social Work deserves emphasis in the investigations regarding the professional formation. Thus, this article, the result of discussions developed in our course conclusion work, aims to reflect on the perceptions of students of the UECE Social Work, course trainees in the field of health, regarding the teaching of health content in the curriculum of this undergraduate course. To do so, we adopted the qualitative research, using the delineations of the bibliographic, documentary and field research, using the semi-structured interview with five students to collect the data. The results of this research evidenced an understanding

\footnotetext{
${ }^{1}$ Graduada em Serviço Social (UECE). E-mail: rebecacosta.ss@gmail.com

${ }^{2}$ Professora do curso de Serviço Social (UECE); Graduada em Serviço Social (UECE); Especialista em Serviço Social, Política Social e Seguridade Social (Faculdade Ratio/Pótere Social); Mestra em Serviço Social, Trabalho e Questão Social (MASS-UECE). E-mail: yashminmichelle@yahoo.com.br

${ }_{3}^{3}$ Professora de Filosofia do Mestrado Acadêmico em Serviço Social (MASS-UECE); Especialista em Economia Política (UECE); Mestra em Filosofia (UFPB/UFMG); Doutora em Educação (UFC); Pósdoutora em Filosofia da Educação (UNICAMP); Doutoranda em Filosofia (UFG). E-mail: cmarinho2004@gmail.com
} 
of the need for a generalist critical education as proposed by ABEPSS, but the prevalence of the perception among the interviewed students about the need for specific disciplines to deal with health content, given the importance of health care as privileged workplaces for social workers and as learning spaces for trainees.

Key-words: Professional training. Health. Social Work.

\section{INTRODUÇÃO}

O/a assistente social tem a gênese da sua inserção na saúde brasileira a partir do trabalho desempenhado nos hospitais, com base no modelo médico clínico, em finais dos anos 1930. Assim como outros/as profissionais, nesta época, ele foi identificado como um contribuinte para o aperfeiçoamento do trabalho médico, desempenhando atribuições consideradas "complementares", como construir vínculos entre as famílias e os/as usuários acompanhados/as, de modo que fosse garantida a manutenção de cuidados após a alta do/a paciente. A prática destes/as assistentes sociais se fundamentava no que se convencionou chamar de Serviço Social de Casos, devido à referência ao funcionalismo que, grosso modo, entendia o "cliente" dos seus serviços como um indivíduo de orientação para a modificação de hábitos e condutas, tomados como inadequados ou desviantes do padrão considerado conveniente (MATOS, 2009, p. 152).

Apesar de a gênese desta inserção haver ocorrido na década de 1930, o Serviço Social apenas foi reconhecido como profissão de nível superior da área da saúde em 1997 (CONSELHO NACIONAL DE SAÚDE, 1997). A permanência neste espaço sócio-ocupacional está repleta de desafios, que surgem, a nosso ver, desde a própria formação profissional em Serviço Social. Assim, cabe-nos questionar: A formação em Serviço Social nos fornece os elementos necessários para o exercício profissional no campo da saúde? Como chegar a este espaço sócio-ocupacional munidos dos conhecimentos mínimos para intervir satisfatoriamente sobre as demandas surgidas? Há necessidade de se priorizarem disciplinas específicas para tratar de determinados conteúdos devido sua relevância como política social e/ou espaço de exercício profissional privilegiado ou uma formação generalista nos fornece as bases para tal? Para os/as estudantes que estagiam em instituições da saúde, a formação profissional na graduação desprivilegia ou potencializa as discussões sobre o conteúdo de saúde? 
Para problematizar estas questões e fomentar o debate a respeito do aprofundamento ou não de determinados conteúdos, como a saúde, nos currículos dos cursos de Serviço Social, o texto que ora apresentamos traz algumas discussões estabelecidas em trabalho de conclusão de curso de graduação (COSTA, 2017), recorrendo à pesquisa de natureza qualitativa e ao uso dos delineamentos da pesquisa bibliográfica, documental e de campo (GIL, 2008). No que se refere ao primeiro delineamento, realizamos revisão de literatura a respeito das categorias: formação profissional, saúde e Serviço Social; quanto ao segundo, entre outras coisas, apropriamo-nos das diretrizes curriculares e dos currículos mínimos de Serviço Social, assim como de dados fornecidos pelo Núcleo de Acompanhamento de Estágio (NAE) do curso de Serviço Social da Universidade Estadual do Ceara (UECE), através de sua "Lista de Informações sobre os Campos de Estágio Credenciados" em 2017; e quanto ao terceiro, estabelecemos o contato com alunas do curso de Serviço Social da UECE.

Os critérios para a seleção destas alunas incluíram estarem cursando a disciplina de Supervisão de Estágio II, estagiando na área da saúde no momento da coleta de dados e já terem cursado a disciplina de Oficina $\mathrm{V}^{4}$. Convidamos estas estudantes por meio da metodologia de indicação sucessiva de entrevistas, também conhecida como "bola de neve", na qual partimos de um/a informante-chave, que nos indica possíveis participantes que, por sua vez, indicam outros/as participantes (DUARTE, 2017). O sexo não foi um critério para a seleção dos/as entrevistados/as, entretanto, a partir da indicação sucessiva, chegamos ao número de oito (8) participantes, todas do sexo feminino, cursando entre $05^{\circ}$ e o $9^{\circ}$ semestre do curso, com faixa etária de vinte e um (21) a vinte e quatro (24) anos. Entre as oito (8) entrevistadas, selecionamos, para este trabalho em específico, apenas cinco (5), as quais estão nomeadas, no corpo deste texto, como "aluna 1 , aluna 2 , aluna 3 , aluna 4 e aluna $5 "$.

A técnica utilizada para a coleta de dados foi a entrevista semiestruturada, que foi coletada em diferentes espaços físicos - como na casa de algumas entrevistadas, no fim do ano de 2017, com auxílio de gravador; posteriormente, sendo transcritas e analisadas. A pesquisa cumpriu todas as normatizações propostas pela Resolução no 196/1996 (CONSELHO NACIONAL DE SAÚDE, 1996),

\footnotetext{
${ }^{4}$ Esta disciplina aborda especificamente o conteúdo de saúde, conforme o currículo vigente até 2016.2.
} 
pela Resolução №. 466/2012 (CONSELHO NACIONAL DE SAÚDE, 2012) e pela Resolução 510/2016 (CONSELHO NACIONAL DE SAÚDE, 2016). Deste modo, todas as entrevistadas forneceram seu consentimento para a utilização dos dados coletados ao assinarem o Termo de Consentimento Livre e Esclarecido, no qual se esclareceram os objetivos, justificativas, métodos utilizados para a coleta dos dados, riscos e benefícios da pesquisa, entre outras coisas, além de reafirmarmos a garantia do sigilo dos nomes das participantes.

Com base no exposto, objetivamos, neste trabalho, refletir sobre as percepções das estudantes da graduação em Serviço Social da UECE, no que se refere ao ensino do conteúdo da saúde no currículo deste curso. Com a finalidade de organizar nossa exposição, elucidaremos dois tópicos centrais: um a respeito do ensino da saúde nos currículos de Serviço Social e um sobre as percepções das entrevistadas, no qual exporemos as reflexões das alunas articuladas à literatura.

\section{ENSINO DA SAÚDE NOS CURRÍCULOS DE SERVIÇO SOCIAL}

A primeira Escola de Serviço Social do Ceará, fundada em 25 de março de 1950, tinha o corpo discente majoritariamente feminino, sendo vinculada à lgreja Católica. Durante o primeiro ano do curso, esta Escola ofertou as seguintes disciplinas: Sociologia; Psicologia; Patologia; Higiene; Enfermagem; Puericultura; Elementos de Direito Constitucional e Administrativo; Direito Civil; Moral; Contabilidade; Estatística; Círculos de Estudos e Serviço Social. Em 1951, foram acrescidas algumas disciplinas mais: Higiene Geral; Higiene do Trabalho; Higiene Escolar; Higiene Mental; Higiene Alimentar; Higiene Social; Direito Penal e Legislação dos Menores; Direito do Trabalho e Legislação Sindical; Doutrina Social da Igreja; Economia Política; e Moral Profissional (SILVA, 2010).

As disciplinas deste último currículo demonstram a existência de uma forte presença do conteúdo da saúde, que se articulava pelo uso de conhecimentos provenientes de outras profissões para dar suporte ao trabalho do/a profissional de Serviço Social, baseando-se nas demandas de outras áreas (SILVA, 2010). Neste currículo também não aparecem disciplinas voltadas ao aprofundamento das discussões filosóficas ou dos fundamentos do próprio Serviço Social, mas sim um direcionamento às demandas trazidas pelo público com o qual geralmente o/a assistente social lidava ou mesmo às exigências de seu mercado laboral. 
Ressaltamos que o corpo docente deste curso, nos anos 1950, era composto em sua maioria por pessoas ligadas à Ação Católica Feminina (Juventude Feminina Católica) e Masculina (União dos Moços Católicos, sendo constituído, usualmente, por médicos, professores e intelectuais ligados às entidades religiosas) e aos membros do Movimento Integralista e do jornal "O Nordeste", além de padres e religiosas (SILVA, 2010, p. 306-309).

No que se refere ao elenco das disciplinas, o quantitativo relacionado à saúde era significativo, pois a profissão atuava sob a influência do positivismo e do empiricismo; posteriormente, do funcionalismo, fazendo com que o trabalho dos/as assistentes sociais ficasse reduzido à manipulação de teorias sobre fatos sociais, gerados em outras áreas.

Sua função [do Serviço Social] limita-se a generalizar no plano prático as verdades produzidas pela Sociologia, Psicologia, Economia, Medicina etc. Cuida apenas da operacionalização desses conhecimentos, que são produzidos pelas Ciências Sociais (SILVA, 2010, p. 306).

Na década de 1960, o Brasil passou por um período de mudanças sociais, políticas e econômicas, demarcadas pelo desenvolvimentismo e também pelo golpe de $1^{\circ}$ de abril de 1964, que deflagrou o início do regime político ditatorial da autocracia burguesa (PAULO NETTO, 2005). Como era de se esperar, este contexto incentivou mudanças no direcionamento dos cursos de Serviço Social brasileiros. Desse modo, o currículo mínimo dos cursos de Serviço Social, fixado pelo Conselho Federal de Educação em 1962, propôs as seguintes matérias: Introdução ao Serviço Social; Serviço Social de Casos; Serviço Social de Grupos; Desenvolvimento e Organização da Comunidade; Administração em Serviço Social; Psicologia; Sociologia; Pesquisa Social; Economia Social; Direito; Ética; Higiene e Medicina Social (BRASIL, 1962).

No caso do curso de Serviço Social, que a partir de 1975 pertence à UECE ${ }^{5}$, por um lado, foram acrescidas novas disciplinas ao seu currículo e, por outro lado,

\footnotetext{
${ }^{5}$ Vale ressaltar que o Curso de Serviço Social da Universidade Estadual do Ceará (UECE) foi incorporado a esta instituição apenas em 05 de março de 1975, sendo um dos cinco primeiros cursos constituintes desta. A gênese deste curso remonta à Escola de Serviço Social vinculada ao Instituto Social de Fortaleza, que era administrado pela Congregação da Sociedade das Filhas do Coração de Maria, estando agregado à Universidade Federal do Ceará (UFC) em seus primeiros anos de existência. Sua criação ocorreu oficialmente em 25 de março de 1950. Disponível em: http://www.uece.br/servicosocial/index.php/historicodocurso. Acesso em: 10 dez. 2018.
} 
as de caráter religioso foram colocadas como eletivas (optativas) (SILVA, 2010, p. 304-306). Dessa forma, observamos uma espécie de "enfraquecimento" curricular do vínculo estabelecido entre o curso de Serviço Social da UECE e a Igreja Católica, com o "respaldo das questões levantadas pelas ciências sociais e humanas, principalmente em torno da temática do 'desenvolvimento' e de suas repercussões na América Latina" (BRAVO; MATOS, 2009, p. 201, grifos dos autores).

Tais modificações socio-históricas ${ }^{6}$ rebateram também no Movimento de Reconceituação do Serviço Social latino-americano, que estabeleceu a crítica ao conservadorismo na profissão, ao Serviço Social "tradicional" (PAULO NETTO, 2005, p. 154), defendendo um Serviço Social de feições próprias, distanciado da importação acrítica dos métodos e construído sob novos conceitos e teorias (RAICHELIS, 2006) ligadas à "militância cívico-política", à aproximação ao marxismo e ao "compromisso com as classes populares" (BARROCO, 2010, p. 141). Segundo Paulo Netto (2005, p. 154, grifos do autor), "a reflexão profissional" com base na erosão do "Serviço Social tradicional" se desenvolveu em três direções, marcando o processo de renovação do Serviço Social brasileiro, quais sejam: a perspectiva modernizadora, a perspectiva de reatualização do conservadorismo e a perspectiva da intenção de ruptura.

Este processo de renovação contribuiu com a aproximação da formação profissional em Serviço Social às ciências sociais, à antropologia, à psicologia e ao marxismo, reafirmando o anseio de separarmo-nos do conservadorismo profissional. Iniciou-se, assim, o processo de laicização da profissão, ao mesmo tempo em que foram retiradas disciplinas com caráter "biologicista" dos currículos dos cursos de Serviço Social brasileiros (PAULO NETTO, 2005, p. 155-157).

No final da década de 1970 e início da década de 1980, eclodiu no cenário nacional o Movimento de Reforma Sanitária, orientado pela resistência ao complexo médico-industrial; ao modelo de formação baseado na especialização e

\footnotetext{
${ }^{6}$ Lembremos, por exemplo, do desenvolvimentismo, da Aliança para o Progresso, da Revolução cubana (RAICHELIS, 2006).

${ }^{7}$ A primeira etapa de aproximação entre o Serviço Social e o marxismo ocorreu na década de 1960/1970 e foi marcada por momentos de profunda efervescência política, social e cultural, devido à ditadura militar, aliada à militância (TAVARES, 2013; BARROCO, 2010). Esta esteve vinculada de início à educação popular, tendo em Paulo Freire sua influência mais determinante, mas também esteve ligada aos setores da esquerda cristã progressista. Muitos/as dos/as assistentes sociais vinculados/as a esta posição partiram do posicionamento dos cristãos de esquerda e estavam engajados na Movimento de Educação de Base (MEB) ou se organizaram em torno do trabalho de Cultura Popular baseado em Paulo Freire ou ainda sofriam a influência da Juventude Universitária (JUC) (AGUIAR, 2011).
} 
fragmentação do conhecimento; e à visão da doença como fenômeno estritamente biológico (NOGUEIRA; MIOTO, 2009). Com efeito,

[...] a principal proposta da Reforma Sanitária é a defesa da universalização das políticas sociais e a garantia dos direitos sociais. Nessa direção, ressalta-se a concepção ampliada de saúde, considerada como melhores condições de vida e de trabalho, ou seja, com ênfase nos determinantes sociais; a nova organização do sistema de saúde por meio da construção do SUS, em consonância com os princípios da intersetorialidade, integralidade, descentralização, universalização, participação social e redefinição dos papéis institucionais das unidades políticas (União, Estado, municípios, territórios) na prestação dos serviços de saúde; e efetivo financiamento do Estado (CONSELHO FEDERAL DE SERVIÇO SOCIAL, 2010, p. 19).

Dos anos 1970 para os anos 1980, o Serviço Social brasileiro passou por profundas alterações: seu Código de Ética de 1965, onde coexistiam os pressupostos do tomismo e do liberalismo ${ }^{8}$ foi reformulado para o Código de Ética de 1975, com a reafirmação do "conservadorismo tradicional" por meio da "adequação às demandas da ditadura" (BARROCO, 2010, 128-130), em favor do que Paulo Netto (2005, p. 154) chamou de "reatualização do conservadorismo". Em março de 1970 também foram fixados os mínimos de conteúdo para os cursos de Serviço Social no Brasil, organizados num currículo mínimo que correspondia às matérias do Ciclo básico: Sociologia; Psicologia; Economia; Direito e Legislação Social; e Teoria do Serviço Social; e as do Ciclo Profissional: Serviço Social de Casos; Política social; Ética Profissional; Serviço Social de Grupo; e Serviço Social de Comunidade (BRASIL, 1970). Ao mesmo tempo, cabe sinalizar que em 1972, teve lugar a proposta precursora da "intenção de ruptura", com o Método $\mathrm{BH}$, que através de um viés de "segunda mão" apropriou-se de Marx (PAULO NETTO, 2005, p. 154-159).

Em 1982, houve a formulação de um novo currículo mínimo para os cursos de Serviço Social, tendo entre suas disciplinas para a Área básica: Filosofia; Sociologia; Psicologia; Economia; Antropologia; Formação Social, Econômica e Política do Brasil; Direto e Legislação Social, e para a Área Profissional: Teoria do Serviço Social; Metodologia do Serviço Social; História do Serviço Social; Desenvolvimento da Comunidade; Política social; Administração em Serviço Social; Pesquisa em

\footnotetext{
${ }^{8}$ Não podemos deixar de destacar que apesar disso, no ano de 1967, a "perspectiva modernizadora" irrompeu com a divulgação do Documento de Araxá (PAULO NETTO, 2005, p. 154).
}

Cadernos Cajuína, V. 4, N. 2, 2019, p.39 - 61.

ISSN: 2448-0916 
Serviço Social; Ética Profissional em Serviço Social; Planejamento social (BRASIL, 1982). A disciplina de Metodologia do Serviço Social foi a responsável por incluir pela primeira vez o debate marxista na graduação, por meio de ledores e comentadores da obra de Marx, como Harnecker e Althusser. A inserção de autores marxistas neste período chegou inclusive a ser considerada por alguns, como reflexo do ecletismo (QUIROGA, 1991, p. 83; 88-89; 91-92).

Devemos ressaltar que a revisão curricular de 1982, de modo geral, não apresentou em seu escopo uma discussão relevante acerca do conteúdo da saúde. $\mathrm{Na}$ verdade, seu foco foram os elementos que ofereciam subsídios principalmente à prática profissional do/a assistente social, a partir da "questão social", objeto de trabalho e razão de ser desta profissão.

No fim dos anos 1980, tivemos a publicação do Código de Ética de 1986, "expressão formal da ruptura ética com o tradicionalismo do Serviço Social" (BARROCO, 2010, p 170). Os avanços expressos por ele, principalmente quanto à dimensão ético-política fizeram com que a profissão assumisse um papel de aliança com a classe trabalhadora, rompendo com a neutralidade e com o conservadorismo que antes vigorava (BARROCO, 2010).

Em 1986, aconteceu a $8^{\text {a }}$ Conferência Nacional de Saúde, um marco na trajetória da política de saúde, em decorrência do relatório produzido a partir dela, responsável por dar suporte às negociações entre os/as envolvidos/as com o movimento da Reforma Sanitária e os/as responsáveis pelo texto da Carta Magna, que seria aprovada em 1988. Neste relatório constava a proposta de elaboração de um sistema de saúde público e de qualidade, a ser incluído no texto constitucional. Assim, em meio a muita movimentação política, resistência e luta, a Constituição Federal de 1988, terminou por instituir a seguridade social como direito, composta pelas políticas de assistência social, previdência social e saúde (CONSELHO FEDERAL DE SERVIÇO SOCIAL, 2010).

Precisamos referir que apesar desta Constituição proporcionar muitas garantias na perspectiva dos direitos sociais, a saúde, assim como outras políticas sociais, sofreu com a contrarreforma do estado neoliberal, principiada nos anos 1990

\footnotetext{
${ }^{9}$ Grosso modo, a "questão social" pode ser definida pela célebre passagem de lamamoto (2010), como sendo: "o conjunto das expressões das desigualdades da sociedade capitalista madura, que tem uma raiz comum: a produção social é cada vez mais coletiva, o trabalho torna-se mais amplamente social, enquanto a apropriação dos seus frutos mantém-se privada, monopolizada por uma parte da sociedade" (IAMAMOTO, 2010, p. 27, grifos da autora).
} 
(BEHRING; BOSCHETTI, 2008). Para superar as habituais crises do capitalismo, organizações econômicas impuseram a adoção de medidas de liberalização, desregulamentação e privatização, sobretudo sobre as políticas sociais, ocasionando a transferência do Estado para "as mãos da população", a responsabilidade sobre as expressões da "questão social", diminuindo, ao mesmo tempo, suas funções de proteção sobre o social, outrora garantidas pela Constituição Federal: agora, as políticas passariam a ser focalizadas, privatizadas e a exigirem critérios para sua concessão (RAVAGNANI, 2010, p. 95).

No contexto das relações de produção e reprodução capitalistas configurouse na década de 1990 um quadro de profundas transformações, que se refletiram na contrarreforma do Estado neoliberal sobre a educação superior, gerando consequências para a universidade pública, gratuita, laica e de qualidade, que se viu tensionada pela iniciativa privada (LIMA, 2007). Neste mesmo período, a categoria dos/as assistentes sociais aprovou a Lei de Regulamentação da Profissão (Lei nº 8662/1993) e publicou o Código de Ética do/a Assistente Social ${ }^{10}$ (BRASIL, 2012), ambos de 1993, além de divulgarem as Diretrizes Curriculares de $1996^{11}$. Estes três documentos afirmaram a direção social hegemônica da categoria profissional dos/as assistentes sociais, em prol do projeto societário das classes trabalhadoras, fundamentando seu projeto ético-político (PAULO NETTO, 2009).

É com o projeto ético-político da profissão, que avançamos para a construção, consolidação e divulgação de um Serviço Social crítico, embasado em debates e discussões acerca da teoria, da prática, dos métodos e da formação profissional. Este projeto foi e ainda é de suma importância para os/as assistentes sociais, pois legitimou um posicionamento profissional diante das instituições, usuários/as, entidades representativas e sobre si mesmo (BARROCO, 2010, p. 175-178).

Entre os elementos constitutivos deste projeto ético-político, podemos considerar: "a explicitação de princípios e valores ético-políticos"; "a matriz teórico-

\footnotetext{
${ }^{10}$ Estas diretrizes se constituíram como o resultado da reformulação do Código de 1986, sendo aprovadas em 13 de março de 1993. Refletem os avanços da categoria diante das discussões em torno da ética e dos novos valores assumidos pela categoria, expressando o compromisso com os/as usuários/as dos serviços prestados e com a construção de uma nova ordem societária. Este documento tem como valor ético central a liberdade, assim como traz outros princípios éticos percebidos pela categoria como horizonte para seu trabalho profissional (BRASIL, 2012).

${ }_{11}$ As novas Diretrizes Curriculares de 1996, pautaram-se em 200 oficinas locais, realizadas de 1994 a 1996 nas 67 Unidades Acadêmicas filiadas à ABESS (Associação Brasileira de Ensino em Serviço Social), 25 oficinas regionais e 2 nacionais (ASSOCIAÇÃO BRASILEIRA DE ENSINO EM SERVIÇO SOCIAL, 1996).
} 
metodológica em que se ancora"; "a crítica radical à ordem social vigente [...]"; e as "lutas e posicionamentos políticos acumulados pela categoria [...]" (TEIXEIRA; BRAZ, 2009, p. 191). Na perspectiva de Teixeira e Braz (2009, p. 191-192), os componentes que dão materialidade aos elementos mencionados são: "a produção de conhecimentos no interior do Serviço Social", "as instâncias político-organizativas da profissão" e "a dimensão jurídico-política da profissão".

Sendo assim, o/a assistente social, como profissional de nível superior da saúde, vem desempenhando suas ações - com base em seu projeto ético-político em equipes da atenção básica, em centros clínicos, em ambulatórios especializados e em hospitais (COSTA, 2009), ou seja, nos níveis de atenção primário, secundário e terciário. Isto demonstra que o interesse teórico e laborativo dos/as assistentes sociais pela saúde, pode se referir particularmente às possibilidades de inserção no mercado de trabalho neste espaço sócio-ocupacional e à importância da política de saúde para o Brasil a partir do final dos anos 1980, ao ser entendida como um direito universal.

Entretanto, este interesse não rebate efetivamente na formação profissional com a presença da temática da saúde nas instituições de ensino de Serviço Social brasileiras, considerando que $35 \%$ destas ainda não introduziram em seus currículos a referida temática (UCHÔA, 2007) e que a recomendação da Associação Brasileira de Ensino e Pesquisa em Serviço Social (ABEPSS) é a de que o perfil do bacharel em Serviço Social seja o de um profissional com formação intelectual e cultural generalista crítica (ASSOCIAÇÃO BRASILEIRA DE ENSINO E PESQUISA EM SERVIÇO SOCIAL, 1996; BRASIL, 1999).

\section{PERCEPÇÕES DAS ESTUDANTES SOBRE O ENSINO DO CONTEÚDO DE SAÚDE NO CURSO DE SERVIÇO SOCIAL DA UECE}

A matriz curricular do curso de Serviço Social da UECE vigente (integralmente) até $2016.2^{12}$ contava com trinta e três (33) disciplinas obrigatórias, quatro (4) eletivas, quatro (4) seminários temáticos e cinco (5) oficinas. Além de

\footnotetext{
${ }^{12}$ Cabe ressaltar que um novo Projeto Pedagógico do Curso de Serviço Social - bacharelado (o que inclui um novo currículo) foi implantado para o curso de Serviço Social da UECE, em 2017.1, tendo o total de 1802 créditos. No presente momento, os dois currículos encontram-se com disciplinas sendo ofertadas. Disponível em: Disponível em: <http://www.uece.br/servicosocial/index.php/projetopedagogicodocurso>. Acesso em: 5 abr. 2018.
} 
atividades acadêmicas complementares que iam do primeiro ao oitavo semestre. $\mathrm{O}$ conteúdo de saúde estava presente no currículo de Serviço Social da UECE em algumas disciplinas obrigatórias e em outras eletivas ${ }^{13}$, porém as primeiras eram ofertadas em caráter de oficinas e seminários ${ }^{14}$. Incluía também duas atividades essenciais: o estágio supervisionado obrigatório e a elaboração do Trabalho de Conclusão de Curso. De acordo com o relato das entrevistadas, a matriz referida tinha cinco (5) disciplinas obrigatórias contemplando o assunto "saúde" em suas ementas: Teorias Psicológicas, Seminário de Serviço Social I, Supervisão de Estágio em Serviço Social I, Supervisão de Estágio em Serviço Social II e Oficina V.

A gente pode aprender um pouco sobre a Psicologia, né? A gente estudou um pouco as matrizes da Psicologia e a professora abordou rapidamente sobre a saúde mental, mas a disciplina focou mais nos conceitos de Freud e outros teóricos da Psicologia (Aluna 1).

Em Seminário I, a gente viu algumas coisas sobre os campos de atuação do Serviço Social, mas a professora focou mais nos campos de saúde, falou também sobre os projetos societários e projeto éticopolítico (Aluna 2).

Em estágio, a professora falou sobre as políticas de estágio e "pincelou" sobre a saúde porque a maioria da sala estagiava na área. Daí falou sobre os Parâmetros para Atuação na Área da Saúde. Não aprofundou porque não deu tempo, mas ela mostrou o interesse de abordar mais coisas relacionadas à saúde. Por isso eu digo que "pincelou", porque o conteúdo foi bem superficial, não deu pra aprofundar (Aluna 3).

Oficina $V$ foi a primeira disciplina que foi abordada de verdade a política de saúde. A professora passou textos sobre o SUS, as leis que regulam o sistema, também falou sobre Reforma Sanitária. Uma pena que foi rápido e não teve profundidade do conteúdo (Aluna 4).

Em relação às disciplinas eletivas, o currículo do curso contava com sete (7) disciplinas que abordavam o conteúdo da saúde: Introdução à Tanatologia, Psicologia Social e Saúde, Seguridade e Serviço Social, Saúde Mental e Trabalho

\footnotetext{
${ }^{13}$ As disciplinas obrigatórias correspondem ao conjunto de disciplinas que não podem ser deixadas de serem cursados pelos/as alunos/as para a obtenção do diploma de graduado no curso em apreço. As disciplinas eletivas compõem um rol de disciplinas, entre as quais os/as alunos/as podem optar cursar para compor a carga horária mínima de créditos necessários à integralização do curso, que são adicionadas às disciplinas obrigatórias.

${ }^{14}$ De acordo com o Projeto Pedagógico do Curso de Serviço Social da UECE, as Oficinas são espaços de vivências que permitem o trabalho operativo de temáticas, instrumentos e técnicas, posturas e atitudes, já os Seminários se constituem como momentos de aprofundamento de temas relevantes, tratados sob diferentes enfoques, objetivando o detalhamento de abordagens voltadas para a problematização e a formação de um pensar crítico propositivo. Ambos possuem $34 \mathrm{~h} / \mathrm{a}$ e 2 créditos curriculares (UNIVERSIDADE ESTADUAL DO CEARÁ, 2012).
} 
nas Organizações, Serviço Social e Saúde, Planejamento e Políticas de Saúde, Práticas Alternativas de Saúde. No entanto, as entrevistadas relataram haverem sido ofertadas somente Seguridade e Serviço Social e Introdução à Tanatologia até aquele momento, afirmando que há algum tempo as demais disciplinas não eram oferecidas. Para elas, este problema decorre da insuficiência de professores para lecioná-las, reduzindo a variedade de opções entre as disciplinas eletivas. Esta realidade é um reflexo da contrarreforma do Estado frente à educação superior pública, onde se inclui a formação profissional em Serviço Social (LIMA; PEREIRA, 2009; LIMA, 2007). Conforme uma de nossas entrevistadas:

Optativa eu só fiz Tanatologia, mas conheço uma menina que fez Seguridade e Serviço Social. Acho que só foi ofertada só uma vez porque falta professor para assumir a disciplina. Tá faltando professor para as disciplinas obrigatórias, daí não tem como eles ofertarem uma disciplina optativa se falta em uma obrigatória. Essa disciplina devia ser obrigatória! (Aluna 5).

As afirmações trazidas pela Aluna 5 refletem a lamentável realidade de muitas instituições públicas de ensino superior brasileiro: faltam-se recursos, quer sejam materiais ou de estruturas físicas, quer sejam recursos humanos, isto é, profissionais vinculados às instituições por meio de vínculos trabalhistas efetivos, opostos aos contratos temporários, precarizados e terceirizados, típicos da era da acumulação flexível (ANTUNES, 2009), que colaboram com a naturalização da "superexploração do trabalho" (MOTA; AMARAL, 2006, p. 37).

Lima e Pereira (2009, p. 36) esclarecem que, com efeito, a proposta do Estado neoliberal para o ensino superior brasileiro se fundamenta em três perspectivas principais: para o projeto político-pedagógico, ela propõe a subalternização da articulação entre ensino, pesquisa e extensão nas universidades públicas, principalmente para os cursos das áreas de ciências humanas e ciências sociais aplicadas; para o financiamento da política de educação superior, ela incentiva a privatização de setores ou espaços de estudos e pesquisas das instituições públicas, o aumento da quantidade de instituições privadas de ensino superior, assim como oferece isenção fiscal para o mercado da educação privada; e, por fim, para o trabalho docente, ela estimula a precarização pela via dos salários, das condições de trabalho, do "produtivismo acadêmico" e da competitividade por verbas financeiras de organizações de fomento à pesquisa. 
Além das disciplinas supramencionadas, o curso de Serviço Social da UECE conta com algumas atividades extracurriculares envolvendo a temática da saúde. Elas estão inseridas dentro da tríade de indissociabilidade entre ensino, pesquisa e extensão nas universidades brasileiras. Sendo assim, encontramos o Laboratório de Estudos e Pesquisas em Seguridade Social e Serviço Social (LASSOS) ${ }^{15}$, um espaço aberto para alunos/as da universidade que buscam conhecer as discussões sobre a dimensão estratégica da seguridade social no Brasil, constituída pelas políticas de saúde, previdência e assistência social, como um lugar profícuo para o debate em torno do conteúdo de saúde. Além dele, os/as estudantes não apenas do curso de Serviço Social da UECE, mas de outros cursos relacionados às profissões consideradas como do âmbito da saúde, dispõem da inserção - por meio de processo seletivo - no PET-Saúde ${ }^{16} /$ GraduaSUS que contempla o debate entre a interdisciplinaridade e a integração universidade-serviço-comunidade na perspectiva da gestão participativa, com o propósito de fortalecer os princípios do Sistema Único de Saúde (SUS) ${ }^{17}$. Incorpora também os princípios da educação permanente, educação popular, trabalho em equipe multiprofissional e interdisciplinar.

Atualmente faço parte do LASSOS, mas já fui do PET-Saúde, porém, lá eu tive certa dificuldade porque eles abordam melhor os outros cursos de saúde, tipo, enfermagem e psicologia. O Serviço Social ainda é um pouco restrito dentro do PET (Aluna 4).

O Serviço Social foi incluído como profissão da área da saúde pela Resolução de oㅜ 218, de 06 de março de 1997, do Conselho Nacional de Saúde (CONSELHO NACIONAL DE SAÚDE, 1997), que reafirmou o assistente social, dentre outras categorias profissionais de nível superior, como profissional de saúde. Igualmente, a Resolução CFESS n. 383, de 29 de março de 1999 (CONSELHO FEDERAL DE SERVIÇO SOCIAL, 1999), confirmou esta reafirmação em seu artigo 1‥ Entretanto, é sabido que apesar destas resoluções, socialmente, o Serviço Social carece de uma maior compreensão sobre suas particularidades, significado social como

\footnotetext{
${ }^{15}$ Atualmente, a Profa. Dra. Lucia Conde de Oliveira coordena este laboratório. Informações sobre este e outros laboratórios do curso de Serviço Social da UECE são facilmente encontradas na página do curso.

Disponível

em:

$<\mathrm{http}: / / w w w . u e c e . b r / s e r v i c o s o c i a l / i n d e x . p h p / l a b o r a t o r i o s e g r u p o s d e p e s q u i s a>$. Acesso em: 10 jun. 2018.

${ }^{16} \mathrm{~A}$ sigla PET/Saúde corresponde à Programa de Educação Tutorial em Saúde. Disponível em:

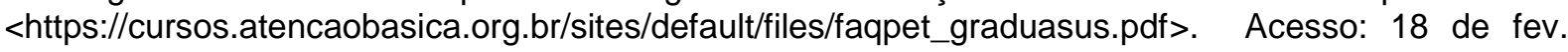
2018.

${ }^{17}$ Universalidade, integralidade, equidade e participação.
}

Cadernos Cajuína, V. 4, N. 2, 2019, p.39 - 61. 
profissão incluída na divisão sócio-técnica do trabalho (YAZBEK, 2009; IAMAMOTO, 2010) e, especificamente, na saúde, sobre o seu fazer profissional (BRAVO; MATOS, 2009; COSTA, 2009).

Ao questionarmos sobre o conteúdo das disciplinas que discutem a política de saúde no currículo do curso de Serviço Social da UECE, as participantes apresentaram percepções diversas quanto ao modo como este conteúdo é abordado.

Quando fiz Oficina V, ela foi ofertada como disciplina de férias, pois tinha acabado de ter uma greve, por isso, o conteúdo ficou prejudicado. Vimos poucos textos e a professora, por mais que tivesse boa vontade, não conseguiu passar o conteúdo como devia. Considero que levando em conta a relevância da temática, ela poderia não ser mais em formato de oficina, pois acho que prejudica o processo de apreensão da matéria (Aluna 5).

Os comentários da Aluna 5 deixam perceber o histórico de greves da UECE, que é bastante considerável e que, se por um lado, garante o atendimento de parte das solicitações reivindicadas através de muita luta e resistência, por outro lado, provoca, em alguns momentos, conforme a Aluna 5, a necessidade de término de disciplinas com celeridade, prejudicando o aprofundamento de alguns conteúdos propostos. Outra entrevistada focou sua opinião na didática dos/as professores/as e na exposição de sugestões para a inclusão de mais conteúdo sobre saúde nas disciplinas ofertadas para o curso de Serviço Social da UECE.

Gostei bastante, apesar da pouca carga horária da disciplina, foi a oficina mais interessante e proveitosa que fiz. A bibliografia foi boa, a história do SUS e da saúde no Brasil. Pra mim uma das melhores professores que tive na minha graduação, maravilhosa! Sugiro, na verdade, é que tenha mais abordagem sobre saúde em outras disciplinas (Aluna 4).

A respeito das considerações postas, vale trazer à tona as inquietações de Juncá (2010, p. 225), quem questiona o não acreditar "na técnica pela técnica", mas sim no buscar o "como" e especialmente o "por que" e o "para que" recorrer a alguma técnica ou estratégia de aprendizagem, que deve conduzir o trabalho dos/as assistentes sociais que atuam na função de docentes, mesmo que não tenham uma formação pedagógica específica para o magistério de Serviço Social no ensino superior. 
Entre as nossas participantes, a Aluna 3 se destacou por considerar a dimensão generalista da formação profissional como um aspecto que pode contribuir para a inserção no estágio na área da saúde, uma vez que superaria a concepção biomédica:

Não posso afirmar que não estudo saúde na disciplina, porque o que estudamos sobre questão social não dá para desvincular da atuação no estágio. $\mathrm{O}$ que a gente aprende sobre vulnerabilidade social, o que é questão social, eu apliquei no estágio. Eu considero muito importante as disciplinas que focalizam a questão social, porque assim a gente pode ter uma percepção mais ampla da sociedade e da nossa atuação. Acho que cabe a cada aluno identificar no seu estágio a expressão e aplicar os conhecimentos de sala de aula (Aluna 3).

A percepção da aluna acima reafirma o posicionamento impresso pela ABEPSS às Diretrizes Curriculares de Serviço Social de 1996 (ASSOCIAÇÃO BRASILEIRA DE ENSINO E PESQUISA EM SERVIÇO SOCIAL, 1996; BRASIL, 1999) no que se refere à formação acadêmico-profissional, isto é, requerer uma formação generalista crítica. Sendo assim, o perfil do/a bacharel em Serviço Social, aprovado pela Comissão de Especialistas de Ensino em Serviço Social recomenda um:

Profissional que atua nas expressões da questão social, formulando e implementando propostas para seu enfrentamento, por meio de políticas sociais públicas, empresariais, de organizações da sociedade civil e movimentos sociais. Profissional dotado de formação intelectual e cultural generalista crítica, competente em sua área de desempenho, com capacidade de inserção criativa e propositiva, no conjunto das relações sociais e no mercado de trabalho. Profissional comprometido com os valores e princípios norteadores do Código de Etica do Assistente Social (BRASIL, 1999, p. 227, grifos nossos).

Esta requisição parte da premissa da necessidade de articulação entre os conteúdos mais amplos das diretrizes curriculares à política de saúde, sem excluir disciplinas que abordem especificamente a política de saúde. Ou seja, disciplinas que discutam as expressões da "questão social" materializariam o conteúdo da saúde, uma vez que referido conteúdo pode aparecer transversalmente aos debates colocados.

Identificamos, através das falas das discentes, uma tendência a considerar que a formação do/a assistente social deveria incluir o debate sobre a saúde e sua relação com a teoria/prática do Serviço Social por meio de disciplinas específicas 
sobre a saúde, não em caráter de Oficinas e/ou Seminários, já que estes dispõem de uma carga horária reduzida. Isto porque disciplinas específicas possibilitariam um conhecimento mais particularizado e aprofundado sobre esta política, o trabalho profissional do/a assistente social nos espaços da saúde e, porque não dizer, sobre os desafios e a materialização do projeto ético-político neste âmbito. Inferimos que a sugestão de disciplinas específicas sobre o conteúdo da saúde se dá devido à ampla requisição de alunos/as do curso de Serviço Social da UECE para estagiar nesta área, além dos/as muitos/as profissionais que exercem suas funções em instituições da saúde.

O estudo da saúde na graduação de Serviço Social é muito importante. A gente já exerce, mesmo que pouco, no estágio, certas atribuições do assistente social e eu acredito que com o ensino de saúde incorporado de maneira mais efetiva no curso, sem ser de forma aligeirada ou em formato de oficina, seria ideal pra que os alunos se preparassem não só pro estágio, mas pra quando se formar também (Aluna 3).

Acho que Oficina $V$ poderia ser uma disciplina que abrangesse com maior profundidade a saúde e que tivesse aula toda semana, igual às outras disciplinas obrigatórias (Aluna 4).

Dados retirados da "Lista de Informações sobre os Campos de Estágio Credenciados" (NÚCLEO DE ACOMPANHAMENTO DE ESTÁGIO/UNIVERSIDADE ESTADUAL DO CEARÁ, 2017) mostraram que das sessenta (60) instituições que recebem esses/as estagiários/as, 48,3\% (29) constituem-se como sendo da área da saúde. Também, dos cento e vinte e sete (127) alunos/as, 58,2\% estagiavam em instituições da saúde, espaço sócio-ocupacional que mais absorve estagiários do curso de Serviço Social da UECE. Estes dados demonstram e reafirmam um resquício histórico da saúde como um dos campos de atuação que mais absorvem profissionais do Serviço Social ${ }^{18}$, tendo sido relevantes os esforços para dar suporte teórico-metodológico e técnico-prático à formação destes estudantes estagiários nessa área específica, conforme suas falas atestaram.

\section{CONCLUSÃO}

${ }^{18}$ A partir de 1945 , o Serviço Social se expandiu no cenário nacional em decorrência do aprofundamento do capitalismo brasileiro e das mudanças ocorridas com o fim da Segunda Guerra Mundial. Com isso, a profissão se ampliou no âmbito saúde e esse setor transformou-se no que mais absorve assistentes sociais (BRAVO; MATOS, 2009). 
Inicialmente, cabe destacar como limite desta pesquisa, a restrição no número de alunas do curso de Serviço Social da UECE entrevistadas, o que nos impossibilita fazer generalizações. Almejamos, entretanto, que este trabalho tenha podido fomentar o debate e contribuir com os estudos sobre a formação profissional em Serviço Social e os elementos que dão impulso à profissão a avançar na consolidação dos pressupostos teórico-metodológicos, ético-políticos e técnicooperativos construídos durante sua história.

Entre os aspectos elucidados pelas sujeitas desta investigação, devemos destacar: primeiro, a ênfase entre as entrevistadas na indicação da necessidade de um maior aprofundamento do estudo do conteúdo relacionado à política de saúde nas disciplinas do curso de Serviço Social da UECE; segundo, a sinalização de uma espécie de "insuficiência" de oferta permanente de disciplinas que poderiam tratar da política de saúde com mais propriedade, uma vez que, conforme exposto, o espaço sócio-ocupacional da saúde recebe muitos estagiários/as do curso de Serviço Social da UECE e emprega uma quantidade considerável de profissionais graduados/as em Serviço Social no país; terceiro, a observação de que no processo de formação profissional no curso de Serviço Social da UECE, por meio da nossa formação generalista crítica, o conteúdo da política de saúde, dentre outros, pode aparecer transversalmente às discussões que consideram as expressões da "questão social" em diferentes âmbitos.

Desse modo, para algumas estudantes participantes desta investigação, caberia oferecer disciplinas específicas para tratar deste conteúdo, não mais em Oficinas ou Seminários, pois apresentam carga horária reduzida. Apesar disso, uma das estudantes justificou a formação generalista crítica proposta pela ABEPSS e adotada pelos cursos de Serviço Social, como o da UECE, como a melhor opção para a discussão sobre a saúde e a relação do Serviço Social com este espaço sócio-ocupacional e esta política social, a fim de se evitar uma "particularização" deste conteúdo, prejudicial à visão de articulação entre os diferentes conteúdos propostos nas disciplinas do currículo deste curso. Nesta discussão, LASSOS e PET Saúde/GraduaSUS foram destacados, inclusive, como espaços diferenciados e abertos à construção de conhecimento e aprendizagem na área da saúde.

A partir das discussões problematizadas, urge dizer que a ABEPSS exige um profissional crítico e reflexivo, colocando a questão da "especialização formativa" dos/as assistentes sociais como uma responsabilidade da pós-graduação. Dito de 
outra forma, a graduação deve se responsabilizar por uma formação generalista crítica, enquanto a pós-graduação deve aprofundar determinados assuntos específicos das discussões profissionais. Isto explica, portanto, a impossibilidade de aprofundar uma série de conteúdos com os quais lidamos, mas que não estão inseridos com profundidade nos currículos dos cursos de Serviço Social, como acontece com o conteúdo da saúde, segundo apontaram nossas entrevistadas.

Além disso, cabe lembrar algumas limitações que afetam o curso de Serviço Social da UECE referidas à ordem da regressão dos direitos, entre os quais o da educação pública de qualidade. Esta regressão está refletida no sucateamento das universidades públicas, na precarização do trabalho dos/as profissionais, na terceirização, entre outros aspectos (LIMA, 2013), e impede a oferta de uma ampla gama de disciplinas eletivas, entre as quais a temática da saúde poderia ser abordada, dentre outras de reconhecida necessidade para o Serviço Social, tais como Língua Brasileira de Sinais ou Relações de gênero. Estas limitações também se expressam nos cortes orçamentários para as bolsas de assistência estudantil, de iniciação científica, extensão e monitoria, que não somente a UECE, mas outras instituições de ensino superior públicas vêm enfrentando.

Consoante a isso, cabe questionar: Há necessidade de se priorizarem disciplinas específicas para tratar de determinados conteúdos devido sua relevância como política social e/ou espaço de trabalho privilegiado ou uma formação generalista crítica nos fornece as bases para tal? Nossa posição é a de que a formação profissional em Serviço Social deve esclarecer a importância de visualizarmos os diferentes conteúdos estudados como articulados, tendo a "questão social" como eixo central (COSTA, 2017). Há ainda a possiblidade de considerarmos a abertura para um leque de disciplinas eletivas que poderiam oferecer discussões "particularizadas" para assuntos de interesse dos/as alunos/as e/ou entendidos pelo corpo docente como necessários às especificidades locais ou regionais, considerando as condições físicas e de recursos humanos das instituições.

A formação profissional, independente de ter como horizonte a área da saúde, deve buscar a capacitação dos/as estudantes, futuros/as profissionais, com base na criticidade, reflexividade e criatividade (IAMAMOTO, 2010) para que possamos identificar as reais necessidades dos/as usuários/as dos serviços de saúde (ou de outros espaços) e com o devido aporte dos direitos sociais, buscar a garantia do acesso. Frisamos que mesmo que o/a assistente social seja reconhecido como 
profissional da saúde, seu objeto de trabalho central segue sendo a "questão social", que engloba, entre outras expressões, os desafios e as demandas trazidas pela política de saúde e seus/suas usuários/as.

\section{REFERÊNCIAS}

ASSOCIAÇÃO BRASILEIRA DE ENSINO EM SERVIÇO SOCIAL/CENTRO DE DOCUMENTAÇÃO E PESQUISA EM POLÍTICAS SOCIAIS E SERVIÇO SOCIAL (ABESS/CEDEPESS). Proposta Básica para o Projeto de Formação Profissional. Proposta Básica para o Projeto de Formação Profissional. Serviço Social \& Sociedade, n. 50, ano XVII, abr. 1996. p. 143-171.

ASSOCIAÇÃO BRASILEIRA DE ENSINO E PESQUISA EM SERVIÇO SOCIAL. Lei de Diretrizes Curriculares. Diretrizes Gerais para o Curso de Serviço Social (com base no currículo mínimo aprovado em Assembleia Geral Extraordinária de 8 de novembro de 1996). Rio de Janeiro, 1996. Disponível em: < http://www.cressrs.org.br/docs/Lei_de_Diretrizes_Curriculares.pdf>. Acesso em: 20 ago. 2015.

AGUIAR, A. G. de. Serviço social e filosofia: das origens a Araxá. 6. ed. São Paulo: Cortez, 2011.

ANTUNES, R. Os sentidos do trabalho: ensaio sobre a afirmação e a negação do trabalho. 2. ed. São Paulo: Boitempo, 2009. (Mundo do trabalho).

BARROCO, M. L. S. Ética e serviço social: fundamentos ontológicos. 8. ed. São Paulo: Cortez, 2010.

BEHRING; E. R.; BOSCHETTI, I. Política social: fundamentos e história. 4. ed. São Paulo: Cortez, 2008. (Biblioteca básica de Serviço Social, v.2).

BRAVO, M. I. S.; MATOS, M. C. de. Projeto ético-político do Serviço Social e sua relação com a Reforma Sanitária: elementos para o debate. In: MOTA, A. E. et al. Serviço Social e saúde: formação e trabalho profissional. 4. ed. São Paulo: Cortez; Brasília, DF: OPAS, OMS, Ministério da Saúde, 2009. p. 167-217.

\section{BRASIL. Código de Ética do/a Assistente Social. Lei 8.662/93 de} regulamentação da profissão. 10. ed. rev. e atual. Brasília: Conselho Federal de Serviço Social, 2012.

BRASIL. MEC/SESu. Comissão de Especialistas de Ensino em Serviço Social. Diretrizes Curriculares - Curso: Serviço Social. Brasília, 1999. In: Temporalis, ano VII, jul./dez. 2007, p. 199-249. (Documentos - Memória do Serviço Social. Pesquisa 
realizada por Dúnia Comerlatto - UNOCHAPECÓ - Priscila Cardoso - PUC/SP - e ABEPSS).

, Comissão de Ensino Superior. Parecer n. 286, aprovado em 10 de outubro de 1962. Estabelece o currículo mínimo do Curso de Serviço Social. Brasília, DF, 1962. In: Temporalis, ano VII, jul./dez. 2007, p. 203. (Documentos - Memória do Serviço Social. Pesquisa realizada por Dúnia Comerlatto - UNOCHAPECÓ - Priscila Cardoso - PUC/SP - e ABEPSS).

, Conselho Federal de Educação. Parecer n. 242/70, aprovado em 13 de março de 1970. Fixa mínimos de conteúdo e duração do Curso de Serviço Social. Brasília, DF, 1970. In: Temporalis, ano VII, jul./dez. 2007, p. 213-216. (Documentos - Memória do Serviço Social. Pesquisa realizada por Dúnia Comerlatto UNOCHAPECÓ - Priscila Cardoso - PUC/SP - e ABEPSS).

, Conselho Federal de Educação. Resolução n.6 de 23 de setembro de 1982. Fixa mínimos de conteúdos e duração do Curso de Serviço Social. Diário Oficial, 13 de outubro de 1982. Brasília, DF, 1982. In: Temporalis, ano VII, jul./dez. 2007, p. 221-223. (Documentos - Memória do Serviço Social. Pesquisa realizada por Dúnia Comerlatto - UNOCHAPECÓ - Priscila Cardoso - PUC/SP - e ABEPSS).

CONSELHO FEDERAL DE SERVIÇO SOCIAL. Parâmetros para atuação de assistentes sociais na saúde. Brasília: CFESS, 2010. (Série Trabalho e Projeto Profissional nas Políticas Sociais).

. Resolução CFESS no 383, de 29 de março de 1999. Caracteriza o assistente social como profissional de saúde. Disponível em: <http://www.cfess.org.br/arquivos/resolucao_383_99.pdf>. Acesso em: 5 jun. 2018.

CONSELHO NACIONAL DE SAÚDE. Ministério da Saúde. Resolução ํo 510, de 7 de abril de 2016. Diário Oficial da União, Brasília, DF, 24 maio, 2016, Seção 1, n. 98, p. 44-46. Disponível em:

<http://bvsms.saude.gov.br/bvs/saudelegis/cns/2016/res0510_07_04_2016.html>. Acesso em: 3 abr. 2018.

. Ministério da Saúde. Resolução no 466, de 12 de dezembro de 2012. Trata de pesquisas em seres humanos e atualiza a Resolução oㅡ 196. Diário Oficial da União, Brasília, DF, 13 jun., 2013, Seção 1, n. 12, p. 59. Disponível em: <http://conselho.saude.gov.br/resolucoes/2012/Reso466.pdf>. Acesso em: 5 jun. 2018.

. Ministério da Saúde. Resolução no 196, de 10 de outubro de 1996. Trata das diretrizes e normas regulamentadoras da pesquisa envolvendo seres humanos. Diário Oficial da União, Brasília, DF, 10 out., 1996. Disponível em: 
http://bvsms.saude.gov.br/bvs/saudelegis/cns/1996/res0196_10_10_1996.html>. Acesso em: 5 jun. 2018.

. Resolução n. 218, de 06 de março de 1997. Diário oficial da União, Brasília, DF, 5 maio, 1997, Seção 1, n. 83, p. 8932-8933. Disponível em: <http://189.28.128.100/dab/docs/legislacao/resolucao218_05_05_97.pdf >. Acesso em: 5 jun. 2018.

COSTA, R. da S. Saúde e formação profissional em Serviço Social: percepções dos/as estudantes estagiários sobre o ensino da política de saúde no curso de Serviço Social da UECE. 2017. 96f. Trabalho de Conclusão de Curso (Graduação em Serviço Social) - Centro de Estudos Sociais Aplicados, Universidade Estadual do Ceará, Fortaleza, 2017.

COSTA, M. D. H. da. O trabalho nos serviços de saúde e a inserção dos(as) assistentes sociais. In: MOTA, A. E. et al. Serviço Social e saúde: formação e trabalho profissional. 4. ed. São Paulo: Cortez; Brasília, DF: OPAS, OMS, Ministério da Saúde, 2009. p. 304-351.

DUARTE, J. B. Entre os estigmas e a desconstrução: reflexões sobre o tráfico de pessoas para fins de exploração sexual e a identidade de gênero de travestis e de transexuais. 197 f. Dissertação (Mestrado) - Curso de Mestrado Acadêmico em Serviço Social, Trabalho e Questão Social, Centro de Estudos Sociais Aplicados, Universidade Estadual do Ceará, Fortaleza, 2017.

GIL, A. C. Métodos e técnicas de pesquisa social. 6. ed. São Paulo: Atlas, 2008.

Histórico do curso de Serviço Social da UECE. Disponível em: < http://www.uece.br/servicosocial/index.php/historicodocurso >. Acesso em: 10 dez. 2018.

IAMAMOTO, M. V. O serviço social na contemporaneidade: trabalho e formação profissional. 19. ed. São Paulo: Cortez, 2010.

JUNCÁ, D. C. de M. O (des)prazer de ensinar: inquietações de um assistente socialprofessor. Serviço Social \& Realidade, Franca, SP, v. 19, n. 2, p. 219-236, 2010. Disponível em: <https://ojs.franca.unesp.br/index.php/SSR/article/viewFile/456/442>. Acesso em: 10 jun. 2018.

Laboratórios do curso de Serviço Social da UECE. Disponível em: <http://www.uece.br/servicosocial/index.php/laboratoriosegruposdepesquisa>. Acesso em: 10 jun. 2018. 
LIMA, K. Contra-reforma na educação superior: de FHC a Lula. São Paulo: Xamã, 2007.

LIMA, K. R. de S.; PEREIRA, L. D. Contra-reforma na educação superior brasileira: impactos na formação profissional em Serviço Social. Sociedade em Debate, Pelotas, RS, v.15, n.1, p. 31-50, jan./jun. 2009.

MATOS, M. C. de. Cotidiano, Ética e Saúde: o Serviço Social frente à contrareforma do Estado e à criminalização do aborto. 2009. 272 f. Tese (Doutorado em Serviço Social) - Pontifícia Universidade Católica de São Paulo, São Paulo, 2009. Disponível em: <http://livros01.livrosgratis.com.br/cp110675.pdf>. Acesso em: 12 nov. 2017.

MOTA, A. E.; AMARAL, A. S. do. Reestruturação do capital, fragmentação do trabalho e Serviço Social. In: MOTA, A. E. (Org.). A nova fábrica de consensos: ensaios sobre a reestruturação empresarial, o trabalho e as demandas do serviço social. 3. ed. São Paulo: Cortez, 2006. p. 23-44.

NOGUEIRA, V. M. R.; MIOTO, R. C. T. Desafios atuais do Sistema Único de Saúde - SUS e as exigências para os assistentes sociais. In: MOTA, A. E. et al. Serviço Social e saúde: formação e trabalho profissional. 4. ed. São Paulo: Cortez; Brasília, DF: OPAS, OMS, Ministério da Saúde, 2009. p. 218-241.

NÚCLEO DE ACOMPANHAMENTO DE ESTÁGIO (NAE) DO CURSO DE SERVIÇO SOCIAL DA UNIVERSIDADE ESTADUAL DO CEARÁ (UECE). Lista de Informações sobre os Campos de Estágio Credenciados em 2017. NÚCLEO DE ACOMPANHAMENTO DE ESTÁGIO/UNIVERSIDADE ESTADUAL DO CEARÁ, 2017. Disponível em: <http://www.uece.br/nae/>. Acesso em: 5 out. 2017.

PAULO NETTO, J. Ditadura e Serviço Social: uma análise do Serviço Social no Brasil pós 64. 15. ed. São Paulo: Cortez, 2005.

PET/Saúde corresponde à Programa de Educação Tutorial em Saúde. Disponível em: <https://cursos.atencaobasica.org.br/sites/default/files/faqpet_graduasus.pdf>. Acesso: 18 de fev. 2018.

Projeto pedagógico do curso Projeto Pedagógico do Curso. Curso de Serviço Social - Bacharelado. Implantado em 2017.1. Disponível em:

<http://www.uece.br/servicosocial/index.php/projetopedagogicodocurso>. Acesso em: 5 abr. 2018.

QUIROGA, Consuelo. Invasão positivista no marxismo: manifestações no ensino da metodologia no serviço social. São Paulo: Cortez, 1991. 
RAICHELLIS, R. História do Serviço Social no Brasil. In: CFESS. Agenda 2006. Brasília: CFESS, 2006.

RAVAGNANI, C. L. C. A Saúde na Formação Profissional em Serviço Social. 2010. 190 f. Dissertação (Mestrado em Serviço Social) - Faculdade de História, Direito e Serviço Social, Universidade Estadual Paulista "Júlio de Mesquita Filho", Franca, SP, 2010.

SILVA, N. T. de F. e. As relações sociais e o Serviço Social no Ceará 1950/1960. In: COSTA, L. F. A.; BEZERRA, L. M. P. S.; PIO, M. C. (Orgs.). Fragmentos do passado do presente: 60 anos do Serviço Social no Ceará. Fortaleza: Eduece, 2010. p. 267-343.

TAVARES, Maria Augusta. Marx, marxismos e Serviço Social (editorial). R. Katál., Florianópolis, v. 16, n.1, p. 9-11, jan./jun. 2013. Disponível em: $<$ http://www.scielo.br/scielo.php?script=sci_pdf\&pid=S1414->.

TEIXEIRA, J. B.; BRAZ, M. O projeto ético-político do Serviço Social. In: CFESS, ABEPSS. Serviço Social: Direitos sociais e competências profissionais. Brasília, DF: CFESS, ABEPSS, 2009. p. 185-200.

UNIVERSIDADE ESTADUAL DO CEARÁ. Projeto Político-Pedagógico do Curso de Serviço Social. Fortaleza: UECE, 2012. Disponível em:

<http://www.uece.br/servicosocial/index.php/projetopedagogicodocurso>. Acesso em: 11 nov. 2017.

UCHÔA, R. Resultados da pesquisa Serviço Social interfaces com a saúde: o ensino da política de saúde na formação profissional dos assistentes sociais no Brasil. Temporalis, São Luis, ano 7, n. 13, p. 185-200, jan./jun. 2007.

YAZBEK, M. C. O significado sócio-histórico da profissão. In: CFESS, ABEPSS.

Serviço Social: Direitos sociais e competências profissionais. Brasília, DF: CFESS, ABEPSS, 2009. p. 125-142. 